\title{
'Blow-outs' in the retinal pigment epithelium
}

\author{
BURTON G GOLDSTEIN AND PETER REED PAVAN
}

From the Department of Ophthalmology, University of South Florida, Medical Center, Tampa, Florida, USA

SUMmaRY A hole was detected in the epithelium of a retinal pigment epithelium (RPE) detachment in two patients. Leakage through the hole led to an elevation of the overlying neurosensory retina in each case. The resulting vision was 20/70 in one eye and 20/30 in the other. The defects in the RPE occurred in a setting different from that usually seen with tears in the pigment epithelium and had a different clinical appearance.

Two patients were seen who had a defect in the epithelium of a retinal pigment epithelium (RPE) detachment underlying a neurosensory retinal elevation. These defects were confirmed by stereobiomicroscopy and stereophotography. They were not similar to the RPE rips or tears which have been previously described. ${ }^{1-4}$ Fluorescein angiography demonstrated intense leakage through the defects in each case. In one patient the evolution of the defect suggested that build-up of fluid pressure in the RPE detachment led to a 'blow-out', causing the defect and subsequent intense leakage with its overlying neurosensory detachment. We believe our patients had a variant of central serous choroidopathy, and the observations made here on the aetiology of the

Correspondence to Peter Reed Pavan, MD, USF Medical Clinics, 12901 North 30th Street, Tampa, Florida 33612, USA.

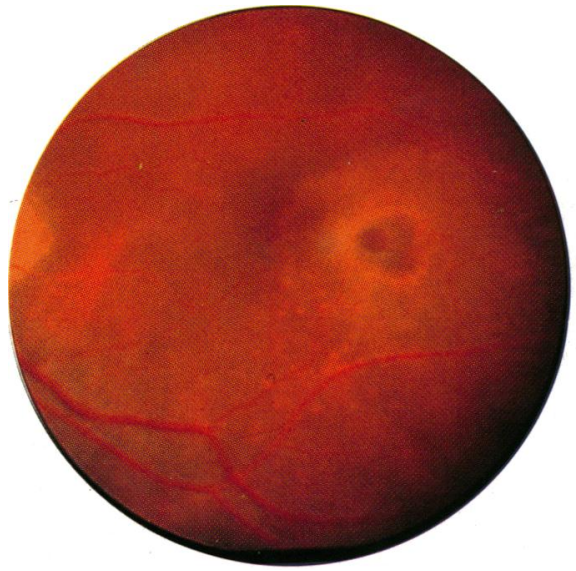

RPE defects may be applicable to all cases of this disease.

\section{Case reports}

\section{CASE 1}

In November 1984 a 50-year-old man was examined who had noted a gradual decrease in vision of his left eye over the preceeding three months. He had had a cardiac transplant 15 months earlier and was taking cyclosporin, prednisone, frusemide and hydralazine. The best visual acuity was 20/30 in the right eye and $20 / 70$ in the left eye with a mild hyperopic shift in comparison with his current correction. The Amsler grid testing and fundus examination in the right eye were normal. In the left eye there was a $1 \frac{1 / 2}{2}$ disc diameter neurosensory detachment centred inferotemporal to fixation (Fig. 1). The edge of the

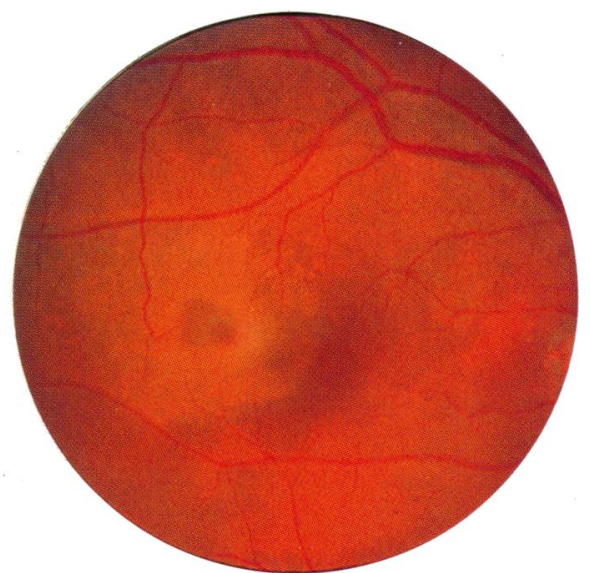

Fig. 1 Case 1. Left eye stereopair: 11/2 disc diameters of subretinal fluid with RPE defect at the dome of an RPE detachment (white dot is artefact). 


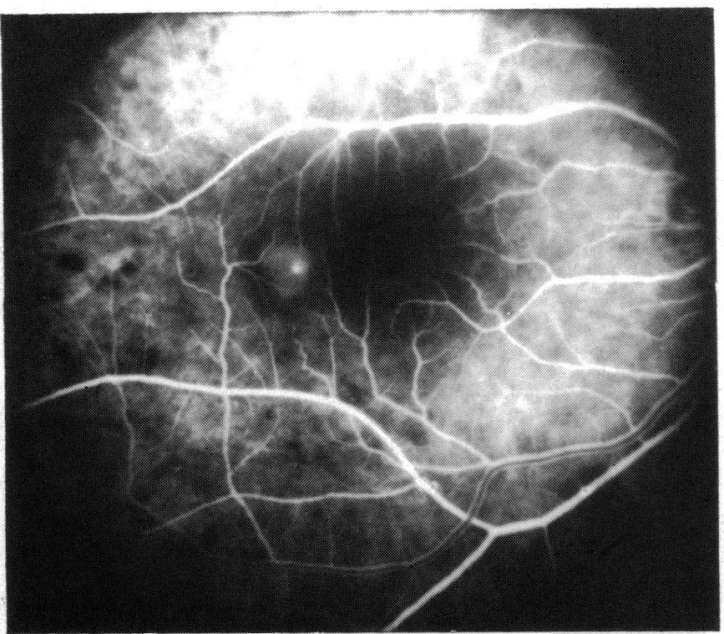

Fig. 2

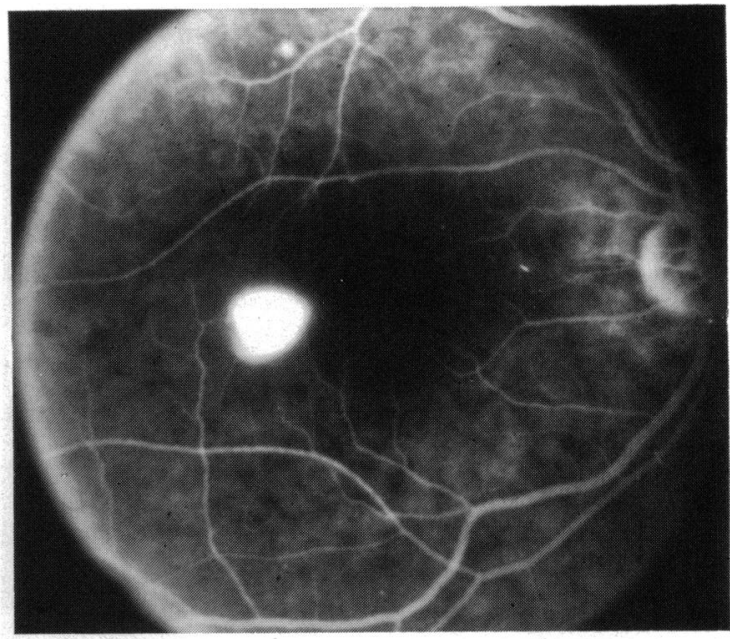

Fig. 3

Figs. 2,3 Case 1. Fluorescein angiograms reveal early pinpoint hyperfluorescence in the area of the RPE defect, with progressive fluorescence through the defect into the subretinal space in the later frame. Note transmission defects temporally.

subretinal fluid just reached the centre of the macula. Underlying the central one-third of the subretinal fluid was an RPE detachment with a $400 \mu \mathrm{m}$ defect in the RPE at its apex.

Fluorescein angiography revealed early even filling of the RPE detachment (Fig. 2). At the apex of the detachment a hot spot was seen which correlated with the RPE defect seen clinically (Fig. 3). The defect leaked dye early and progressively into the subretinal

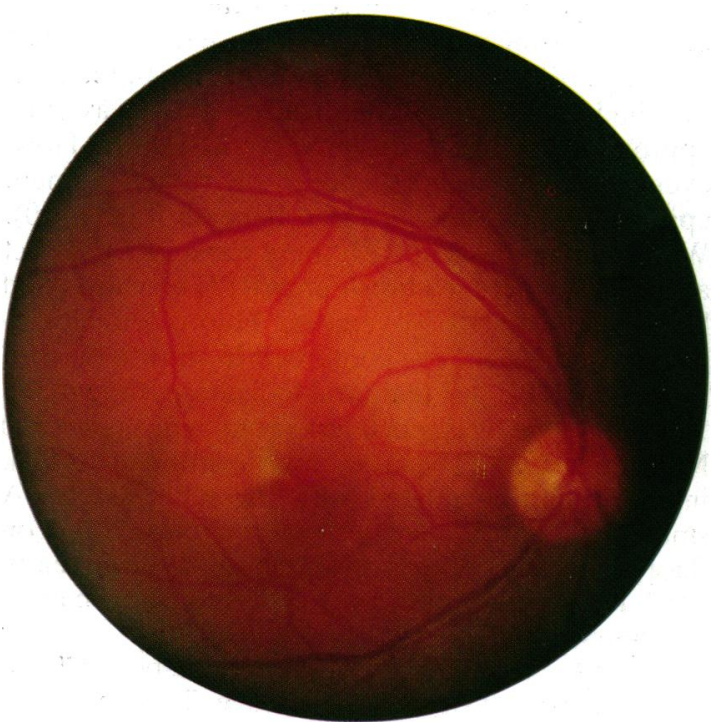

Fig. 4 "Case 2. Right eye, 10 November 1983. One disc diameter subretinal fluid with greyish elevation of $R P E$ just temporal to fixation. space. In late views the definition of the RPE detachment was lost owing to the accummulation of dye in the overlying subretinal space. Late phase photographs in the right eye were normal. The patient died soon after the examination.

CASE 2

On 10 November 1983 a 31-year-old man presented with a two-day history of metamorphopsia in the

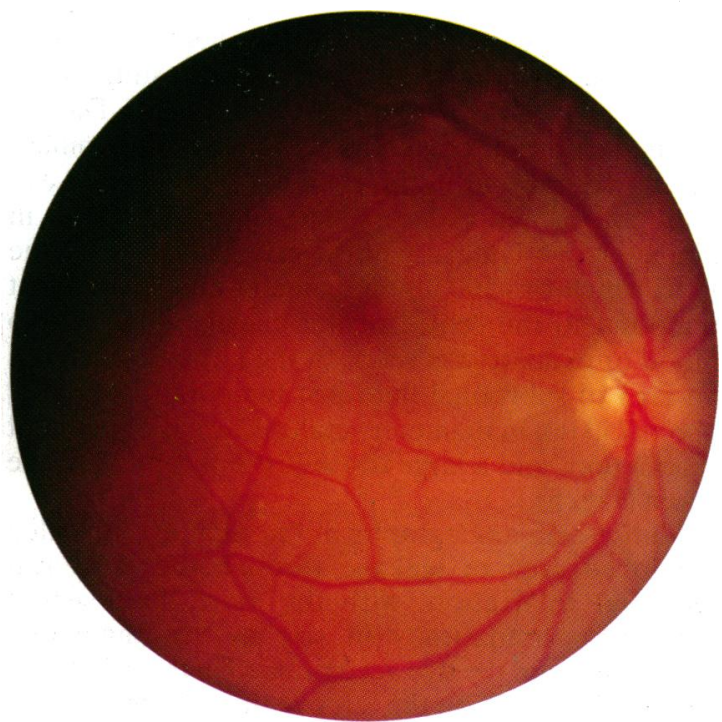

Fig. 5 Case 2. Left eye, 10 November 1983. Scattered subtle areas of pigment rarefaction and small area of subretinal fluid temporal to the disc. 


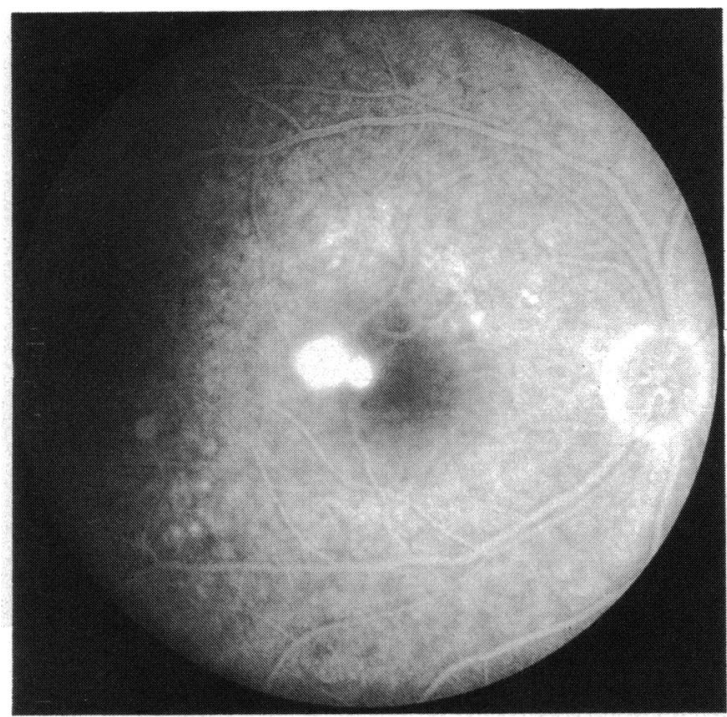

Fig. 6

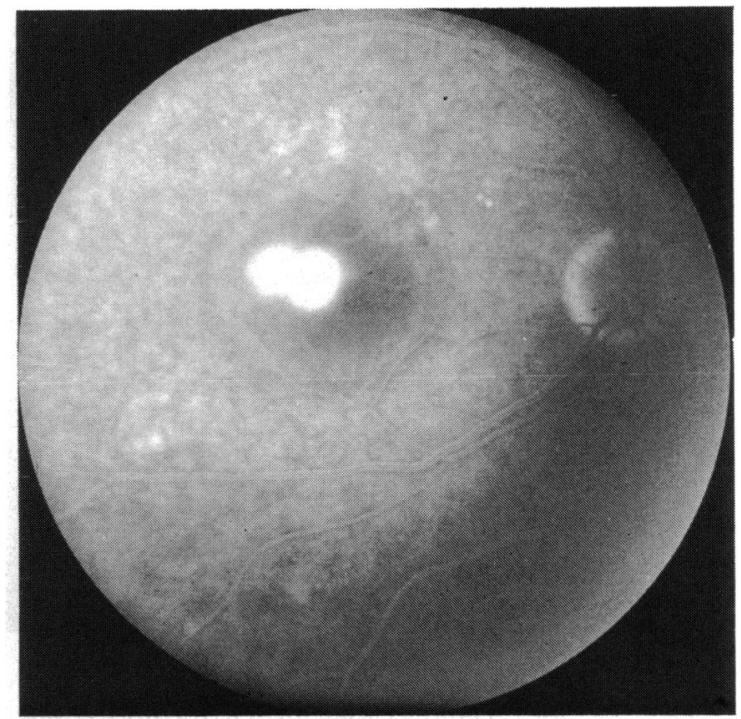

Fig. 7

Figs. 6,7 Case 2. Right eye, 10 November 1983. Fluorescein angiogram reveals bilobed hyperfluorescence with early more intense leak from the nasal lobe, which increases dramatically as the angiogram progresses (temporal lobe offluorescence is probably a small RPE detachment).

right eye. He had had an aortic resection four years previously for a traumatic aneurysm and was on propranolol and triamterene plus hydrochlorothiazide (Dyazide) for hypertension.

The best acuity was $1 / 200$ in the right eye and 20/20 in the left eye with a mild hyperopic refraction. Retinoscopy revealed a. 2 dioptre increase in hyperopia in comparison with his spectacle correction in the right eye. On Amsler grid testing in the right eye there was a large central 'grey spot'. The left eye had a normal grid pattern. An afferent pupillary defect was present in the right eye. In the right eye there was a neurosensory detachment $1500 \mu \mathrm{m}$ in diameter overlying a whitish grey elevation of the RPE which was $500 \mu \mathrm{m}$ in diameter and located just temporal to the centre of the macula (Fig. 4). No blood or exudate was seen. In the left eye there was an area of subretinal fluid just temporal to the disc about $750 \mu \mathrm{m}$ in diameter, multiple areas of pigment rarefaction, and a large druse just inferonasal to the fovea (Fig. 5).

Fluorescein angiography in the right eye revealed a bilobed area of leakage through the RPE just temporal to fixation, with the more nasal aspect increasing dramatically in size as the angiogram progressed and the dye accumulated in the subretinal space (Figs. 6, 7). In the left eye there were multiple transmission defects in the posterior pole, some of which correlated with areas of pigment rarefaction seen clinically, and a slow pooling of dye in the neurosensory detachment just temporal to the disc (Fig. 8).

On 14 November 1983 the subretinal fluid in the right eye had increased to involve the entire area within the arcades (Fig. 9). On 22 November the subretinal fluid in the right eye was the same, but in the left eye it had extended into the centre of the macula, causing the vision to decrease to $20 / 50$. On 4 January 1984 the neurosensory elevation in the right eye had decreased dramatically, so it was only approximately $1 \frac{1 / 2}{2}$ disc diameters in extent. However, a yellowish opalescence of the retinal pigment epithelium had now appeared beneath it (Fig. 10). Within this opalescent RPE there was an RPE defect at the spot where a whitish grey RPE elevation had been noted on 10 November. Fluorescein angiography in the right eye continued to show a bilobed leak in the RPE just temporal to fixation, though the 'temporal lobe' was much less prominent than on 10 November 1983. The nasal lobe continued to leak intensely and correlated with the RPE defect. A small RPE detachment was seen clinically and on fluorescein angiography inferonasal to the fovea in the left eye in an area previously noted to have a transmission defect.

On 28 February 1984 the vision remained 1/200 in the right eye and $20 / 50$ in the left eye. The amount of subretinal fluid in the right eye had decreased further, and there was a small white subretinal scar where the RPE defect had been on 4 January (Fig. 


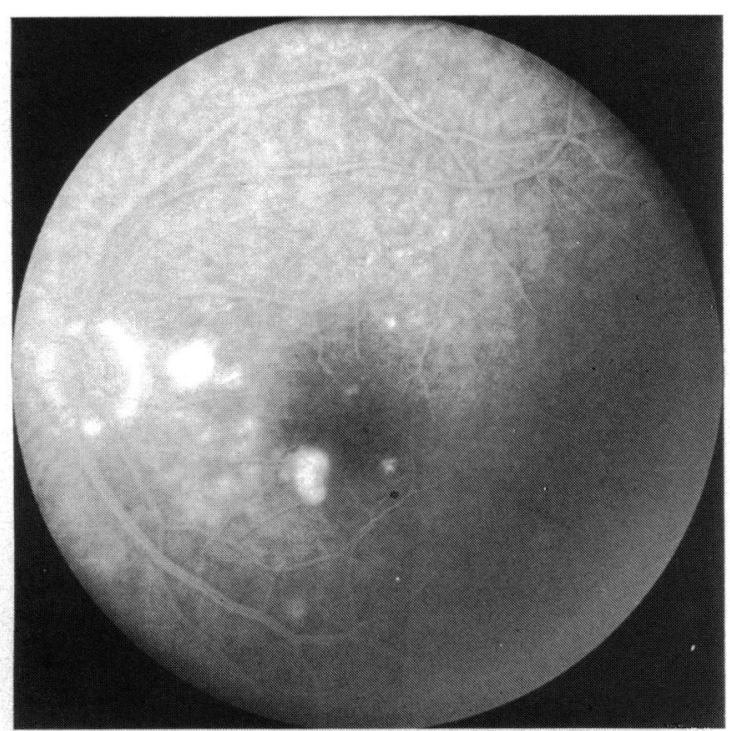

Fig. 8 Case 2. Left eye, 10 November 1983. Multiple transmission defects with slow leak present just temporal to the disc and early collection of dye inferonasal to fovea probably representing an RPE detachment.

11). The scar was hypofluorescent on angiography (Fig. 12.). The left macula had a decreased amount of subretinal fluid just temporal to the disc.

On 27 March the patient's acuity was unchanged in the right eye but in the left eye had fallen to 20/200. In the left macula there was a neurosensory detachment over the RPE detachment on clinical examination. On angiography the RPE detachment stained more intensely, with blurring of its borders in the later phases, suggesting accumulation of dye in the overly-

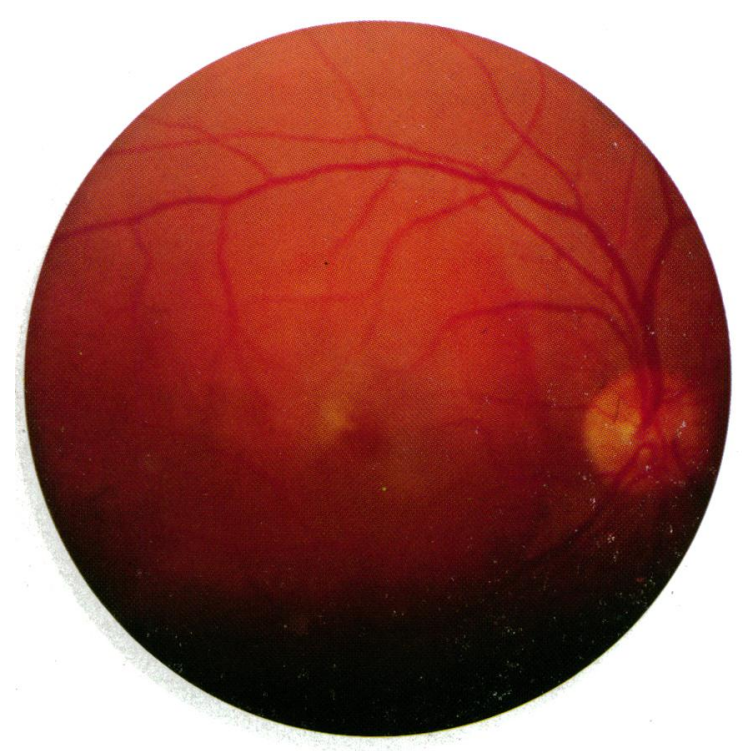

Fig. 9 Case 2. Right eye, 14 November 1983. Four days after Fig. 4, showing marked increase in subretinal fluid.

ing subretinal space. The clinical examination and angiogram of the right eye remained the same.

By May 1986 vision had improved to 20/30 in the right eye and 20/25 in the left, with a flat pigmented macular scar present.

\section{Discussion}

These two cases appeared to represent a distinct entity apart from rips or tears in the pigment epithelium. They both occurred in middle aged men in the setting of severe central serous choroidopathy.
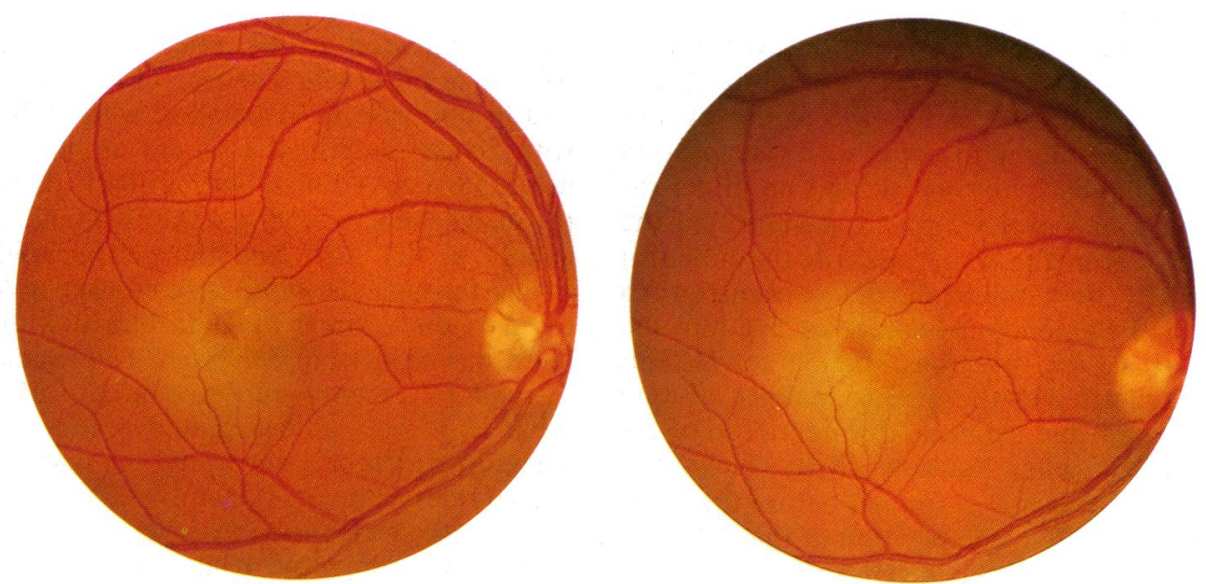

Fig. 10 Case 2. Right eye stereopair, 4 January 1984: 11/2 disc diameters opalescence of RPE with central RPE slit-like defect corresponding to area in Fig. 4 of RPE alterations. 


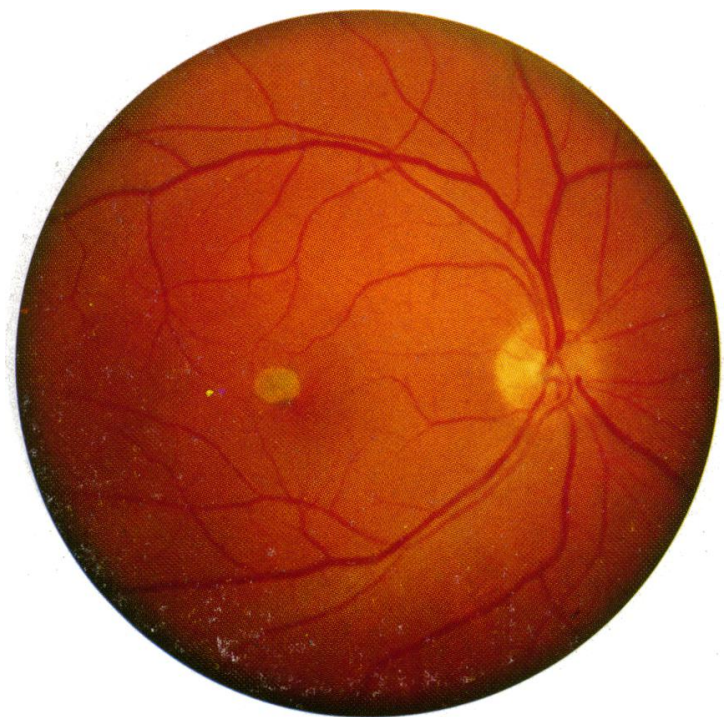

Fig. 11 Case 2. Right eye, 28 February 1984. $500 \mu \mathrm{m}$ subretinal scar with hyperpigmented centre with no evidence of subretinal fluid, retinal oedema, blood, or exudate.

Neither case was associated with laser treatment, macular degeneration in the fellow eye, or with haemorrhage or exudate commonly seen in patients with rips or tears in the pigment epithelium. Both RPE defects were located in the perifoveal regions and were associated with visual loss. The RPE defects did not appear along the margin of an RPE detachment as is typical of an RPE rip ${ }^{2-4}$ but rather at the dome of the detachment. The edges of the defect were not retracted as is common in an RPE rip. ${ }^{1}$ In both cases angiography showed early intense fluorescence at the site of the defect, which then progressively leaked dye into the subretinal space. The opalescence in case 2 appeared by stereobiomicroscopy to be an opalescent change in the RPE rather than a change in the transparency or debris on the photoreceptors. Since the defect was at the level of the RPE by stereobiomicroscopy, with visualisation of the choriocapillaris through it and an intact slit beam of the retina overlying it, it seemed that the RPE defect was in the same layer as the adjacent opalescent RPE. In patient 2 the defect occurred at a site which had tremendous leakage of dye into the subretinal space by previous angiography. This evolution suggests that the intense leakage of fluid led to weakening and eventual disintegration of the overlying RPE cells, causing 'RPE blow-out'. Although case 1 was not examined before the RPE blow-out had occurred, the position of the defect at the site of intense leakage at the apex of an RPE detachment implies its evolution was similar to that observed in case 2 .

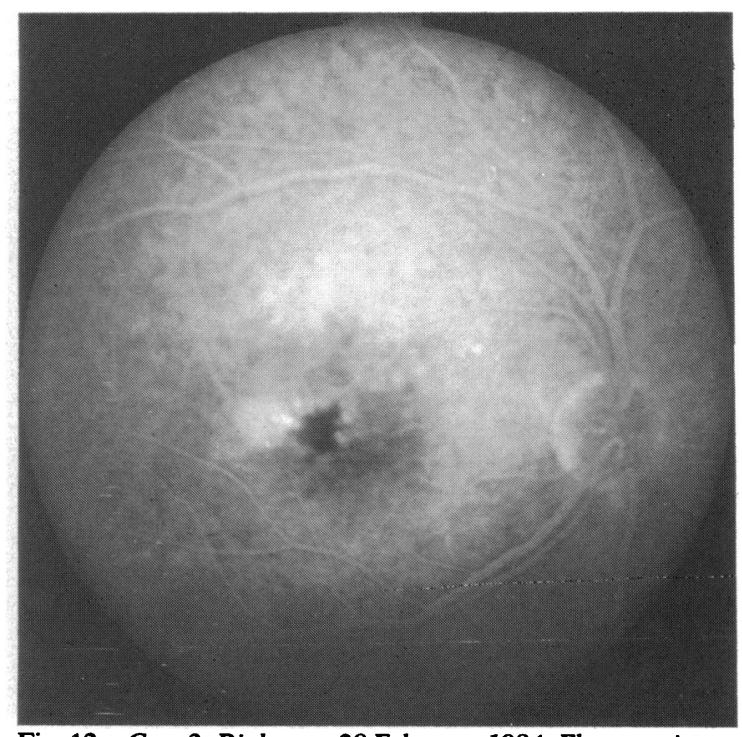

Fig. 12 Case 2. Right eye, 28 February 1984. Fluorescein angiogram reveals no leakage from areas of previously intense leakage.

Gass $^{5}$ described a series of patients similiar to ours. They had exudative retinal detachments with areas of serous RPE detachments and small pinpoint leaks in the RPE detachment that leaked into the subretinal space. Photocoagulation of the RPE detachment resulted in resolution of the RPE detachments. The majority of patients were healthy. Some of the exudative retinal detachments were bilateral, and some spontaneously resolved, as in our case 2 . He considered his patients had a variant of central serous choroidopathy. DeBuestros et al. ${ }^{6}$ recently described three similiar cases; however, none of these cases were described in association with holes in the RPE. Swanson et al. ' described cases of tears in the RPE which appeared to be related to traction from subretinal fibrosis in a setting of retinal detachment and in one case in association with a chorioretinal scar. Schat ${ }^{8}$ described a patient similiar to ours. $\mathrm{He}$ was a 58-year-old man with an RPE detachment in the macula and overlying subretinal fluid. There was a hole in the RPE and the choriocapillaries was visible through the hole. Argon laser was administered to the entire RPE detachment with improvement of vision from $8 / 200$ to $20 / 30$. Sunakawa and Tsukahara' recently reported a case of an 'acute' RPE leak with an associated serous detachment treated with argon laser round the tear, resulting in retinal reattachment and improved vision.

Our cases were probably severe variants of central serous choroidopathy. It appeared that the intense leakage across the RPE caused the disintegration of these cells. There is both clinical ${ }^{10}$ and experimental ${ }^{11}$ 
evidence that photocoagulation of the pigment epithelium causes restoration of the pigment epithelial barrier. Possibly these cases of unusually intense leakage might have a better prognosis if photocoagulation treatment is administered early in the clinical course. There is no anatomical defect that has been detected with central serous retinopathy ${ }^{12}$ (and Gass JDM, personal communication), so that the leak through the RPE is presumably a functional defect. Whether the origin of this defect is choroidal or is a primary RPE disturbance is not clear. It is interesting that, although intense leakage was present in our case, no exudate accumulated in contrast to its frequent accompaniment with subretinal neovascularisation.

The authors thank Moira Burke, MD, for kindly allowing the examination of case 2 .

\section{References}

1 Cantrill HL, Ramsay RC, Knoblock WH. Rips in the pigment epithelium. Arch Ophthalmol 1983; 101: 1074-9.
2 Hoskin A, Bird AC, Sehmi K. Tears of detached retinal pigment epithelium. Br J Ophthalmol 1981; 65: 417-22.

3 Meredith TA, Braley RE, Aaberg TM. Natural history of serous detachments of the retinal pigment epithelium. Am J Ophthalmol 1979; 88: 643-51.

4 Decker WL, Sanborn GE, Ridley M, Annesley WH Jr, Sorr EM. Retinal pigment epithelial tears. Ophthalmology 1983;90:507-12.

5 Gass JD. Bullous retinal detachment-an unusual manifestation of idiopathic central serous choroidopathy. Am J Ophthalmol 1973; 75: 810-21.

6 DeBuestros S, Michels RG, Rice TA, Knox DL. Treatment of idiopathic exudative retinal detachment. Retina 1984; 4: 158-62.

7 Swanson DE, Kalina RE, Guzak SV. Tears of the retinal pigment epithelium. Retina 1984; 4: 115-8.

8 Schatz H. Laser treatment of fundus disease. Pacific Medical Press, 1980: pp76-7.

9 Sunakawa M, Tsukahara I. Tear of the retinal pigment epithelium and serous retinal detachment. Am J Ophthalmol 1985; 100: 488-9.

10 Robertson DM, Ilstrup D. Direct, indirect and sham laser photocoagulation in the management of central serous chorioretinopathy. Am J Ophthalmol 1983; 95: 457-66.

11 Wallow IH. Repair of the pigment epithelial barrier following photocoagulation. Arch Ophthalmol 1984; 102: 126-35.

12 Gass JDM. Stereoscopic atlas of macular disease. St Louis: Mosby, 1972: 41.

Accepted for publication 16 September 1986. 
5 Mitsuya H, Weinhold KJ, Furman PA, et al. 3'-azido- 3'deoxythymidine (BW A509U): an antiviral agent that inhibits the infectivity and cytopathic effect of human T-lymphotropic virus type III/lymphadenopathy-associated virus in vitro. Proc Natl Acad Sci USA 1985; 82: 7096-100.

\section{Cardiac side effects of beta blocker eyedrops}

SIR, The study by Brazier and Smith' of carteolol versus timolol eyedrops suggests that, whatever the theoretical advantages of intrinsic sympathomimetic activity in reducing cardiac side effects, it does not prevent carteolol from inhibiting excercise induced tachycardia. We must therefore remain sceptical in the face of blandishments from the pharmaceutical companies that this and other new beta blockers for ophthalmic use will produce fewer cardiac side effects.

Further studies are required to test whether or not these new drugs provide significant protection against beta blockade of cardiac contractility and peripheral vascular resistance. Perhaps the situation will only become clear when we have sufficient clinical experience of these drugs in the elderly glaucoma population. Meanwhile opthalmologists should report all cases of cardiac and respiratory side effects to the Committee of Safety of Medicines using the familiar yellow cards. J L JAY Tennent Institute of Ophthalmology,

Western Infirmary,

Glasgow G11 6NT

\section{Reference}

1 Brazier DJ, Smith SE. Ocular and cardiovascular response to topical carteolol $2 \%$ and timolol $0.5 \%$ in healthy volunteers. $\mathrm{BrJ}$ Ophthalmol 1987; 72: 101-3.

\section{Notes}

\section{Research grants}

The David Cole Travel fellowship, instituted by Merck Sharp and Dohme in memory of Professor David Cole, will assist a visit to a hospital or research centre during the academic year starting 1 October 1988 . The award will be equivalent to $£ 2000$. The purpose of the award is to enable the successful applicant to gain experience and knowledge in pursuit of a specific project related to glaucoma.

The Glaucoma Group Research grant, sponsored by the International Glaucoma Association, will be available for a research project clinically orientated to glaucoma for 1988 . The award will be equivalent to $£ 2500$. The grant may be used towards salary or project expenses or for buying equipment.

Both these awards are available to medical graduates and non-medical scientists resident in the United Kingdom or the Irish Republic. They may be held concurrently with other awards. Further details and application forms from Dr S Nagasubramanian, Secretary Glaucoma Group, Glaucoma Unit, Moorfields Eye Hospital, High Holborn,
London WCIV 7AN. The closing date for applications is 15 June 1988 . The successful candidate will be informed by August 1988 .

\section{Tenth Interamerican course in clinical ophthalmology}

This will be held in Miami, Florida, on 18-22 October 1988. Details from Interamerican Course, Bascom Palmer Eye Institute, PO Box (016880, Miami, FL 33101, USA.

\section{Geographical ophthalmology}

The next meeting of the International Society of Geographical Ophthalmology will be held jointly with the Ophthalmological Society of East Africa in Nairobi, Kenya, on 3-5 August 1988. There will be symposia on 'Retinal diseases in different geographical settings' and 'Ocular disease due to chlamydia' as well as free papers. Further information from Professor Gordon J Johnson, Director International Centre for Eye Health, 27-29 Cayton Street, London EC1V 9EJ.

\section{Singapore conference}

The XXVI International Congress of Ophthalmology will be held in Singapore on 18-24 March 1990. Details from Dr Arthur S M Lim, c/o Department of Ophthalmology, National University Hospital, Lower Kent Ridge Road, Singapore 0922, Republic of Singapore.

\section{Retinitis pigmentosa}

The 5th International Retinitis Pigmentosa Congress will be held on 4-7 November 1988 at Melbourne, Australia. Details from RP Congress, 46a Oxley Road, Hawthorn, Victoria 3122, Australia.

\section{Prize for outstanding achievement}

The Ludwig Von Sallmann Prize will be awarded at the 8th International Congress of Eye Research to be held on 4-8 September 1988 at the Hyatt Regency Hotel, San Francisco, California. The award of $\$ 30000$ is for an outstanding achievement in ophthalmology and vision. Information and nomination blanks for this award can be obtained from Peter Gouras, MD, Von Sallmann Prize Committee, Columbia University, Box 18, 630 West 168 Street, New York, New York 10032, USA.

\section{Correction}

In the article by Burton G Goldstein and Peter Reed Pavan (BrJ Ophthalmol 1987; 71: 676-81) Dr Goldstein informs us that the following figures were published reversed: Fig 1, right photograph of stereopair; Figs 2, 3, and 5. 